\title{
The Evolutionary Dynamics of Apomixis in Ferns: A Case Study from Polystichoid Ferns
}

\author{
Hong-Mei Liu, ${ }^{1}$ Robert J. Dyer, ${ }^{2,3}$ Zhi-You Guo, ${ }^{4}$ \\ Zhen Meng, ${ }^{5}$ Jian-Hui Li, ${ }^{5}$ and Harald Schneider ${ }^{2,6}$ \\ ${ }^{1}$ Key Laboratory of Southern Subtropical Plant Diversity, Fairylake Botanical Garden, \\ Shenzhen \& Chinese Academy of Sciences, Shenzhen 518004, China \\ ${ }^{2}$ Department of Life Sciences, Natural History Museum, London SW7 5BD, UK \\ ${ }^{3}$ Research Group in Biodiversity Genomics and Environmental Sciences, Imperial College London, \\ Silwood Park Campus, Ascot, Berkshire SL5 7PY, UK \\ ${ }^{4}$ Department of Biological Sciences, Qiannan Normal College for Nationalities, Duyun 558000, China \\ ${ }^{5}$ Computer Network Information Center, Chinese Academy of Sciences, Beijing 100190, China \\ ${ }^{6}$ State Key Laboratory of Systematic and Evolutionary Botany, Institute of Botany, Chinese Academy of Sciences, \\ Beijing 100093, China
}

Correspondence should be addressed to Hong-Mei Liu, sorolepidium@gmail.com and Harald Schneider, h.schneider@nhm.ac.uk Received 19 July 2012; Revised 20 September 2012; Accepted 20 September 2012

Academic Editor: Karl Joseph Niklas

Copyright () 2012 Hong-Mei Liu et al. This is an open access article distributed under the Creative Commons Attribution License, which permits unrestricted use, distribution, and reproduction in any medium, provided the original work is properly cited.

\begin{abstract}
The disparate distribution of apomixis between the major plant lineages is arguably one of the most paradoxical phenomena in plant evolution. Ferns are particularly interesting for addressing this issue because apomixis is more frequent than in any other group of plants. Here, we use a phylogenetic framework to explore some aspects of the evolution of apomixis in ferns and in particular in the polystichoid ferns. Our findings indicate that apomixis evolved several times independently in three different clades of polystichoid ferns. A lineage-wide perspective across ferns indicates a correlation between apomixis and the species richness of lineages; however BiSSE tests did not recover evidence for a correlation of apomixis and diversification rates. Instead, evidence was recovered supporting an association between the establishment of apomixis and reticulate evolution, especially in the establishment of triploid hybrids. Diversification time estimates supported the hypothesis of short living apomictic lineages and indicated a link between the establishment of apomixis and the strengthening of the monsoons caused by the lifting of the Qinghai-Tibetan plateau. In general our results supported the hypothesis for the rare establishment of apomictic lineages, high extinction risks, and low speciation rates.
\end{abstract}

\section{Introduction}

The evolution of asexual reproduction in multicellular eukaryote lineages such as animals, fungi, and plants continues to attract the interests of biologists [1-3]. The prevalence of sexual reproduction in these lineages is paradoxical considering the theoretical advantages associated to asexual reproduction [3, 4]. Hypotheses to explain this paradox have concerned lower rates of speciation and higher rates of extinction in asexual lineages. Essentially, the short-term ecological advantages of asexual reproduction are balanced by the long-term effect of lower diversification rates. This hypothesis is consistent with reported evidence for shortlived apomictic lineages, for example, the derived fern genus Astrolepis [5], and the developmental feature changes required for the loss of sexuality in plants [3]. However, it is inconsistent with other studies that recover evidence for species rich lineages that lack any reported evidence for at least rare sexual events [6,7], and a recent study on the eudicot genus Oenothera, which shows "increasing diversification associated with loss of sexual recombination and segregation" [4]. This conflicting evidence questions 
our general understanding of the evolution of asexual reproduction, and the causes of its uneven distribution among animals and land plants.

Here, we investigate the association of apomixis and changes of diversification rates in a derived group of ferns. Apomixis in ferns is a distinctive form of asexual reproduction that combines the production of unreduced spores (diplospory) and the formation of sporophytes from somatic cells of the prothallium (apogamy) [8-11]. Apomixis is known from different lineages of land plants but is reported to be more common in ferns $[12,13]$. Some reviews suggest estimates for the occurrence of apomixis is up to $10 \%$ of extant fern species globally [12], and up to $17 \%$ in some local fern floras [13]. The high frequencies in ferns contrast strongly with the much lower frequencies of apomictic taxa in angiosperms and gymnosperms $[2,3,14,15]$. However, apomixis is not only unevenly distributed among the major lineages of land plants but also among fern lineages (Figure 1; Table 1). Within the derived ferns, two of the most speciesrich families, Dryopteridaceae and Pteridaceae, comprise approximately $70 \%$ of reported apomictic fern species (Figure 1; Table 1). This pattern suggests that apomixis may be linked to species richness [16]. However, apomixis is rare in several other species-rich families of derived ferns such as Polypodiaceae (Figure 1; Table 1). The conflicting evidence suggests at least one missing factor, such as environmental conditions or karyological traits, for example, hybridization and polyploidy [3]. This highlights the need to consider additional properties, some of which are unique to ferns, when trying to understand the evolution of apomixis in ferns.

Polyploidy and reticulate evolution are strongly linked with the occurrence and establishment of apomixis in both ferns and angiosperms $[5,17-23]$. This link is especially true for triploid and pentaploid taxa $[13,19,23]$. However, several cases of diploid apomictic ferns are known; for example, about $11 \%$ of apomictic species of Pteris are diploids [19,23]. It is also significant that the vast majority of apomictic ferns are reported to be obligate, lacking the ability to reproduce sexually [9], whereas in angiosperms many "apomictic" taxa are facultative, exhibiting a mixed mating system that combines the advantages of sexual and asexual reproduction. This has a large impact on the establishment of apomixis, and the various transition pathways possible.

We also need to consider the similarity in the ecologicalevolutionary potential of sexual, obligate selfing (intragametophytic) ferns. Obligate intragametophytic selfing of polyploids results in fixed heterozygote genotypes that are comparable to apomictic lineages. However, obligate inbreeding appears to be uncommon in ferns, with the majority of ferns reproducing either via obligate outcrossing or mixed mating systems [24, 25].

Finally, the high frequency of apomixis in Japanese ferns [13] indicates a possible geographic influence on the occurrence of apomictic taxa. In angiosperms, apomictic species tend to occupy often more northern distribution ranges than their sexual relatives [26]. But such a northern range effect has not been reported for ferns.
In this study, we address the following issues: (1) the uneven distribution of apomixis in fern lineages, (2) the association of apomixis with polyploidy and hybridization, (3) the association of apomixis and odd ploidy levels, (4) the connection between apomixis and changes in diversification rates, and (5) the link between the establishment of apomixis and geographic distribution and/or geological events. To address these questions, we assessed the reported occurrence of apomixis across ferns and reconstructed the evolution of apomixis in polystichoid ferns. The latter are an outstanding example given our knowledge on the phylogeny of this species-rich lineage of derived ferns [27-36], including the various reports on reticulate evolution and polyploidy [37], and reports on the reproductive biology of these ferns showing a range of modes from obligate outcrossing to apomixis $[34,38,39]$. It has been suggested that apomixis may be restricted to three lineages of polystichoid ferns which all have their putative origin in SE Asia [34]. Thus, we also discuss evidence supporting the hypothesis linking the evolution of apomixis with the strengthening of the monsoon climate due to the rise of the Qinghai-Tibetan plateau from the mid Miocene to Pleistocene [40].

\section{Materials and Methods}

To investigate the occurrence of apomixis and polyploidy in ferns and in particular polystichoid ferns, we carefully reviewed all existing reports on embryo development [39, 41, 42] and chromosome numbers (see http://darwintree.cn/special_topic/fern/home.jsp). The latter were obtained mainly from exploring data accessible in Tropicos (http://www.tropicos.org/), published chromosome number lists [43], and from pertinent publications [37, 44]. In the context of polystichoid ferns, we also used the information provided at David Barrington's Polystichum website (http://www.uvm.edu/ dbarring/polystichum.htm). Where possible, we traced back the original reports to confirm the taxon identity and reported results. However, confirmation of species identity through the study of vouchers was not applicable to the vast majority of the records due to the lack of adequate vouchers, and/or the amount of time and funding required to carry out this practice. This limitation introduces some taxonomic uncertainty given the difficulties of species identification and changes of taxonomic concept over the last 100 years. This problem must be considered especially for single reports of apomixis and/or chromosome numbers per species. In addition, single observations are also insufficient to explore the fixation of reproductive modes and ploidy levels in species. These problems cannot be avoided but we tried to reduce this putative bias as much as possible by scrutinizing the evidence and by integrating different sources of information. In general, apomixis was only accepted for studies that are unlikely to report induced apomixis, meaning apomixis created under laboratory conditions $[39,45]$. A significant problem may be the assumption that no record of apomixis for taxa is the same as the absence of apomixis. To compensate for this shortcoming, we carried out investigations into 


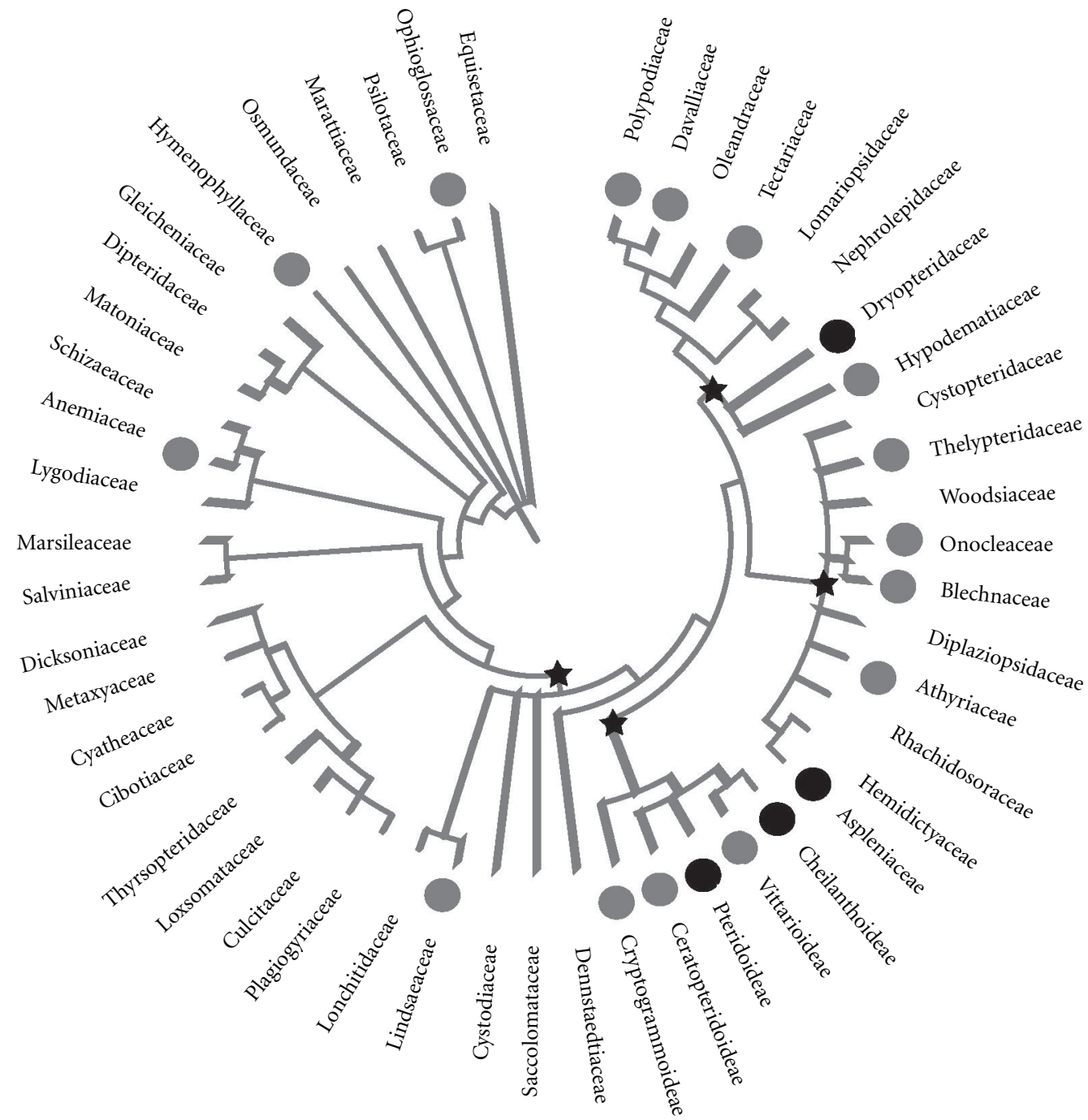

FIGURE 1: Global phylogeny of fern families as recovered in recent phylogenetic analyses [53,61] with some poorly resolved nodes collapsed. Circles indicate occurrence of apomixis in this family. Grey circle: $<5 \%$ of known apomictic fern taxa belong to this family; black circles: $>5 \%$ of known apomictic fern taxa belong to this family. Pteridaceae are replaced by five subfamilies to illustrate the uneven distribution of apomixis in the highly diverse family. Fern families with more than 400 extant species are printed in bold. Stars indicate lineages of importance: 1 = Polypodiales, $2=$ Pteridaceae, $3=$ Eupolypods 1 , and $4=$ Eupolypods 2.

the reproductive biology of polystichoid ferns, particularly Cyrtogonellum (Cyrtogonellum caducum). This was achieved by growing gametophytes from spores to obtain direct observation on the formation of sexual organs and the formation of sporophytic outgrowth with or without fertilization. The results of these experiments were compared with previous reports on the occurrences of apomictic reproduction in these ferns [42].

Cyrtogonellum caducum sporophytes were collected from Guizhou Province, China. Fertile pinnae were kept in clean paper bags under dry conditions until spores were shed. Spores were cultured in plastic containers filled with humus collected together with the sporophytes that was sterilized at $120-130^{\circ} \mathrm{C}$ for thirty minutes. The containers were covered with transparent plastic film, on which two to three small holes were made in order to reduce the risk of contamination and desiccation. The containers were kept in the laboratory and exposed to natural light conditions throughout the experiments. Cultures were moistened with tap water to prevent desiccation and were periodically examined to record the onset of spore germination, the growth of gametophytes, the formation of antheridia and archegonia, and the onset of the development of sporophytes. Theses conditions were not significantly different from conditions used to grow sexual taxa. We can not exclude the possibility of induction of apomixis via cultivation condition and this may need to be addressed in future studies. So far, all reported evidence suggested this taxon to reproduce apomictically in both cultural experiments as well as natural conditions.

We have compiled all data on apomixis in ferns and lycophytes and presented it in a new website "Apomixis in Ferns" (http://darwintree.cn/special_topic/fern/home.jsp). 
TABle 1: Summary of the recorded cases of apomixis in fern families. Natural occurring apomixis (excluding induced occurrences) was reported for about 242 species of ferns. These reports suggest apomictic occurrence of at least $3 \%$ of the currently estimated 10,000 to 11,000 fern species. Species rich fern families ( $>400$ species) are marked in bold. The sequence of families follows Figure 1, families defined as in the most recent classifications of ferns [56, 57].

\begin{tabular}{|c|c|c|c|}
\hline Family & NR APO & ASSO POLY & MULT ORG \\
\hline Equisetaceae & 0 & NA & NA \\
\hline Psilotaceae & 0 & NA & NA \\
\hline Ophioglossaceae & 1 & ++ & NA \\
\hline Marattiaceae & 0 & NA & NA \\
\hline Osmundaceae & 0 & NA & NA \\
\hline Hymenophyllaceae & 8 & ++ & ++ \\
\hline Dipteridaceae & 0 & NA & NA \\
\hline Gleicheniaceae & 0 & NA & NA \\
\hline Matoniaceae & 0 & NA & NA \\
\hline Anemiaceae & 1 & $?$ & NA \\
\hline Lygodiaceae & 0 & NA & NA \\
\hline Schizaeaceae & 0 & NA & NA \\
\hline Marsileaceae & 0 & NA & NA \\
\hline Salviniaceae & 0 & NA & NA \\
\hline Cibotiaceae & 0 & NA & NA \\
\hline Culcitaceae & 0 & NA & NA \\
\hline Cyatheaceae & 0 & NA & NA \\
\hline Dicksoniaceae & 0 & NA & NA \\
\hline Loxsomataceae & 0 & NA & NA \\
\hline Metaxyaceae & 0 & NA & NA \\
\hline Plagiogyriaceae & 0 & NA & NA \\
\hline Cystodiaceae & 0 & NA & NA \\
\hline Lindsaeaceae & 9 & ++ & ++ \\
\hline Lonchitidaceae & 0 & NA & NA \\
\hline Saccolomataceae & 0 & NA & NA \\
\hline Dennstaedtiaceae & 0 & NA & NA \\
\hline Pteridaceae & 84 & ++ & ++ \\
\hline Aspleniaceae & 20 & ++ & ++ \\
\hline Athyriaceae & 16 & ++ & ++ \\
\hline Blechnaceae & 1 & $?$ & NA \\
\hline Cystopteridaceae & 0 & NA & NA \\
\hline Diplaziopsidaceae & 0 & NA & NA \\
\hline Hemidictyaceae & 0 & NA & NA \\
\hline Onocleaceae & 1 & NA & NA \\
\hline Rhachidosoraceae & 0 & NA & NA \\
\hline Thelypteridaceae & 5 & ++ & ++ \\
\hline Dryopteridaceae & 87 & ++ & ++ \\
\hline Hypodematiaceae & 1 & $?$ & NA \\
\hline Lomariopsidaceae & 0 & NA & NA \\
\hline Nephrolepidaceae & 0 & NA & NA \\
\hline Tectariaceae & 1 & $?$ & NA \\
\hline Oleandraceae & 0 & NA & NA \\
\hline Davalliaceae & 2 & ++ & ++ \\
\hline Polypodiaceae & 6 & ++ & ++ \\
\hline
\end{tabular}

NR APO: number of species per family recorded to be apomictic; ASSO POLY: evidence for association of apomixis and polyploidy; MULT ORG: evidence for multiple origins of apomixis in this family considering existing phylogenetic evidence. Symbols: ++: yes, ?: unknown as a result of lack of evidence, NA: not applicable as an absence of apomixis or a single taxon with apomixis.

The website provides basic information about occurrence of apomixis in ferns and lycophytes, including a list of all recorded apomictic taxa as well as the corresponding references.
To enable us to explore the evolution of apomixis in polystichoid ferns, we developed a phylogenetic hypothesis based on $r b c L$ sequence data that were obtained from GenBank in March 2012. We downloaded all sequences available 
for the genera Cyrtogonellum, Cyrtomidictyum, Cyrtomium, Phanerophlebia, and Polystichum. In total 215 accessions were acquired and were manually aligned and visually inspected using Mesquite 2.75 [46]. Sequences of poor quality were excluded if more than one accession per taxon was available. Phylogenetic reconstruction of this data was compared with published phylogenies of polystichoid ferns [27-36] to highlight any conflicts in the phylogenetic relationships observed. Comparisons were specifically made between our results and the consensus tree provided at the Polystichum website (http://www.uvm.edu/ dbarring/polystichum.htm). Several species were found to be polyphyletic and we deleted sequences that were likely due to the result of misidentification. Where possible we checked vouchers but in many cases we needed to trust the identification provided by the colleagues generating these data. In general, the probability of incorrectly identified material was considered to be limited in this dataset because the majority of DNA sequences used was generated by researcher groups that comprised one or several experts in the taxonomy of polystichoids ferns. Finally, we reduced the dataset to have one accession per taxon. This dataset of 143 taxa was then used to reconstruct phylogenetic hypotheses used in this study. To reduce the impact of missing karyological data, we further reduced the dataset to 82 taxa for which the number of chromosomes was known.

Standard methods were used to obtain phylogenetic hypotheses based on the 143-taxon set and 82-taxon set. First, we used jModeltest [47] to determine the best-fit model for both data sets. Then, we carried out maximum parsimony analyses in PAUP 4.0 [48] using heuristic searches with 100 random starting point and default options, and maximum likelihood analyses in PHYML 3.0 [49] as implemented in the plugin for Geneious 5.4. [50]. The latter approach was also used to obtain bootstrap values for the maximum likelihood tree using 1000 bootstrap replicates. Bayesian inference of phylogeny was carried out using MrBayes 3.2.1 [51] and BEAST 1.7.1 [52]. Both Bayesian analyses were carried out using a single partition and the model selected in jModeltest, but BEAST analyses required further parameter choices. These included the assumption of a relaxed molecular clock, a calibration of the onset of the diversification of polystichoid ferns in the form of a log-normal distribution with a standard deviation of 1 and a shift from 0 by $34.5 \mathrm{ma}$ as found in [53], and a Death-Birth speciation process. All Bayesian results were inspected using TRACER 1.5 [54] and FIGTREE 1.3.1 [55] before further usage.

We scored the reproductive biology of each species as sexual (0) or apomictic (1) for all taxa included. The chromosome numbers were used to obtain two characters. First, we scored the taxon to be either diploid (0) or a polyploid (1) without any further differentiation of the ploidy level. Secondly, we scored each taxon as having an even (0) or odd (1) ploidy level, that is, contrasting diploid, tetraploid, hexaploid, and octoploid taxa against triploid, pentaploid, and heptaploid taxa. A few taxa were scored as polymorphic for one or all of these characters. Limitations of the available data were taken into consideration, such as the lack of evidence about the reproductive biology of several diploid taxa nested within apomictic clades. Diploid apomicts were recorded for several derived fern genera [19, $23,58]$ and may also occur in polystichoid ferns. However, we did not have sufficient evidence to reject the alternative that diploids represent sexual taxa. In this study, we explore two assumptions: diploid taxa always represent sexuals versus diploids in apomictic clades reproduce via apomixis. So far, diploid apomictic taxa have not been recorded for polystichoid ferns but we cannot reject their putative occurrence. The link between apomixis and biogeography was inferred by scoring the distribution occurrence either as: within SE Asia (including China, Japan, Korea, and Indochina) or as outside of SE Asia. Taxa occurring in both areas were scored as within SE Asia, assuming this as the area of origin. Information concerning distributions was obtained from GBIF, Tropicos, and publications on polystichoid ferns referred to throughout this study.

These scores were then plotted onto the phylogenetic hypotheses obtained in the analyses of the 143 and 82 taxon datasets. We used maximum parsimony reconstruction with unordered and/or ordered characters as well as maximum likelihood reconstruction with the MK1 model to infer the evolution of these characters. Pagel's test for correlation of characters over a phylogeny [59] was used to infer correlations between the three characters scored: absence/presence of apomixis, ploidy level as diploidy or polyploidy, and absence/presence of odd ploidy levels (e.g., $2 x, 4 x, 6 x$ versus $3 \mathrm{x}, 5 \mathrm{x})$. This test was carried out using the implementation in Mesquite and with the 82-taxon dataset because these analyses cannot be carried out with incompletely scored taxa.

The association of apomixis and diversification rates of polystichoid ferns was investigated using the BiSSE method as implemented in Mesquite [60]. The 0 hypothesis (independence) was compared with the tested hypothesis (dependence) using likelihood ratio tests. Significance of the results was further investigated by comparing the likelihood values of the tested hypothesis with the likelihood distribution based on 1,000 simulated trees. First, we explored the association of the three characters scored with changes in speciation rate, extinction rate, frequency of character state changes, or combinations of these three parameters. Secondly, we inferred the hypothesis of unidirectional change from sexual to apomixis in these ferns by comparing the probabilities of character state changes q01 (sexual to apomictic) and q10 (apomictic to sexual). The results of estimated and fixed (one close to 0 and one close to 1 ) values of q01 and q10 were compared. In the absence of direct reports on the reproductive biology, the putative presence of sexual reproduction or apomictic reproduction was inferred via two assumptions: (1) 32 spores per sporangium indicated apomictic reproduction whereas 64 spores per sporangium indicated sexual reproduction; (2) diploids were assumed to be sexually reproducing despite evidence for diploid apomictic ferns in other fern genera $[19,23,58]$. The reduction of the spore number from 64 to 32 spores was considered as an indicator of apomixis in ferns belonging to the order Polypodiales. This criterion was introduced based on the documented conservation of the spore number in this fern order and the discovered mechanisms of apomixis in 
ferns. This criterion can not be used in other ferns such as tree ferns. Theoretically, some other mechanism may result in the reduction of spores in Polypodiales but not a single case has been convincingly reported. The vast number of observation on the reproductive biology of diploid ferns supports these assumptions but we took care to consider the potential error introduced. The second assumption was expected to increase the signal for putative reversals from apomictic to sexual reproduction. Thus, the effect of this value was inferred by carrying out the analyses by scoring diploids nested within apomictic clades either as apomictic or sexual.

\section{Results}

Phylogenetic analyses and character reconstruction for apomixis and polyploidy showed that apomixis was restricted to three clades in the polystichoid ferns. These three clades were (1) the core Cyrtomium clade, (2) the Cyrtogonellum clade, and (3) the Xiphopolystichum clade (Figure 2). In contrast, polyploidy was found to occur in all clades of polystichoid ferns. However, the occurrence of triploid taxa was restricted to the clades with apomictic reproduction. Apomictic reproduction was confirmed by gametophyte cultures in Cyrtogonellum caducum, based on the observation of sporophytic outgrowths and the lack of archegonia (Figure 3). However, functional antheridia were observed (Figure 3).

Maximum likelihood reconstruction supported a minimum number of three independent origins of apomixis (Figure 2). Apomixis was supported as the ancestral state for the Cyrtogonellum clade $(P>0.95)$, but not for the core Cyrtomium clade $(P=0.05)$ or the Xiphopolystichum $(P=0.5)$. However, the subclades of Xiphopolystichum had probabilities $P=0.50$ and 0.97 , and the subclade of core Cyrtomium had probabilities of $P=0.50$ and 0.03 (Figure 2).

Pagel's test for the correlated evolution of discrete characters on phylogenies provided evidence for significant correlations between apomixis and the occurrence of triploids $(\ln (0)=-53.719693, \ln (1)=-26.701372$, Diff $=27.018321, P<0.01)$, apomixis and polyploidy $(\ln (0)$ $=-74.733399, \ln (1)=-66.158126$, Diff $=8.575273, P<$ $0.01)$, and polyploidy and occurrence of triploids $(\ln (0)=$ $-74.733399, \ln (1)=-66.162897$, Diff $=0.570502, P=0.01)$. Apomixis was also found to be associated with biogeography $(\ln (0)=-57.204702 / \ln (1)=-52.350905$, Diff $=4.845666$, $P=0.02)$.

BiSSE analyses for association of character evolution and diversification rate recovered small differences between log likelihoods of analyses assuming character-independent rates to those assuming character-dependent rates with one or all three parameters (speciation rate $\lambda$, extinction rate $\mu$, and character transition rate q) considered. None of these values were significant considering a $P<0.05$ criterion: $\ln ($ independent $)=-0.164 .15245282, \ln ($ dependent $)=$ -0.163 .6640405 , Diff $=0.4860$.

BiSSE analyses on the frequency of character changes q01 versus q10 did not support the two extreme models with q01 $<<\mathrm{q} 10$ and q01 >> q10 while the model q01 < q10 was found to have the best fit.

\section{Discussion}

Both the global phylogeny of ferns as well as the detailed reconstruction of the evolution of apomixis in polystichoid ferns recovered evidence for multiple origins of apomixis (Figures 1 and 2; Table 1). Examination of previous studies supports the hypothesis that apomixis evolved many times in ferns, and that it occurs with high frequency in some clades and not at all in others (Table 1). Species richness appears to be one factor associated to apomixis at the global level (Table 1), but this association is not supported in the polystichoid fern lineage. In this lineage we did not find a correlation between speciation/extinction rates and apomixis (see results of BiSSE analyses). Nevertheless, the analyses of the polystichoid dataset did support the hypothesised association of apomixis and reticulate evolution involving polyploidy $[5,17,20-23]$. The main caveat here is that polyploidy alone is insufficient to confirm reticulation because chromosome numbers do not provide sufficient evidence to distinguish between auto- and allopolyploidy. However, we suggest that polyploidy is a strong proxy for reticulate evolution and expect similar results to be recovered in more detailed studies of the evolution of apomixis in other fern families.

The polystichoid dataset also showed clear evidence for a correlation between apomixis and the occurrence of triploid and pentaploid taxa. This link may be caused by the capacity for tetraploid and hexaploid hybrids to reproduce via intragametophytic selfing, which results in fixed heterozygosity [62]. This capacity may lead to a reduction in the potential establishment of such apomictic hybrids. In contrast, apomixis is more likely to be established in triploid and pentaploid hybrids, because meiotic incompatibilities at these uneven ploidy levels would result in female sterility. A transition to apomixis in such hybrids would overcome female sterility. Despite the clear evidence for this correlation, it does not answer all questions concerning the origin of apomixis in ferns.

To address these questions we need to consider the limitation of our current knowledge on the occurrence of apomixis in ferns. For example, it is very difficult to estimate the minimum number of times in which apomixis has originated due to ambiguities in reports on the absence/ presence of apomixis. The reproductive biology of many species is poorly or completely unknown. Thus, the absence in reports of apomixis may not always indicate the absence of apomixis in natural populations. Similarly, single reports of apomictic reproduction may also be misleading if apomixis is not a fixed character state of a single recognized taxon. Further reports using cultivated material must be examined carefully because it is possible to confuse experimentally induced apomixis and naturally occurring apomixis [39, 45]. Apomixis can be easily induced in many fern taxa and spontaneous apomixis may happen frequently in nature. For example, we considered the recent report of apomixis 


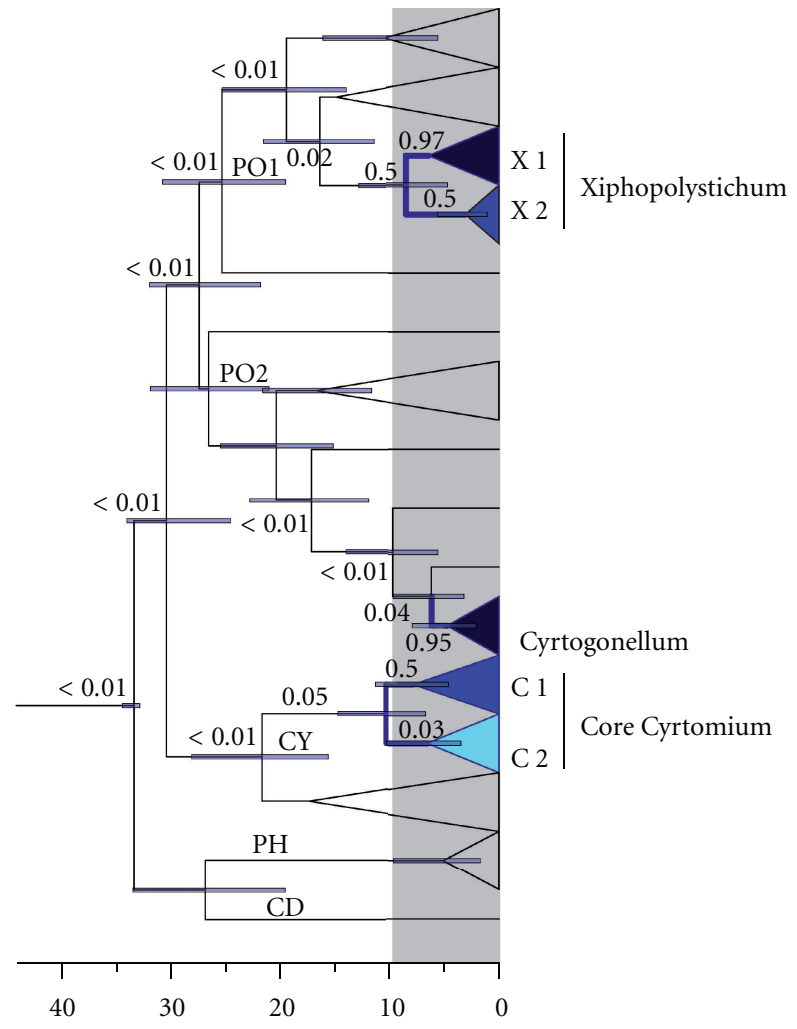

FIGURE 2: Diversification of polystichoid ferns through time as inferred using rbcL chloroplast DNA sequences (obtained from GenBank in March 2012) and Bayesian estimates of divergence times using a relaxed molecular clock model. The shown topology is consistent with the results of published phylogenetic analyses of polystichoid ferns, see also David Barrington's Polystichum website (http://www.uvm.edu/ dbarring/polystichum.htm). The three groups comprising apomictic taxa are indicated as follows: dark color: all or nearly all taxa are reported to be apomictic, middle blue: half or most taxa are reported to be apomictic, and bright blue: minority of apomictic taxa. Thick blue branches: earliest putative origin of apomixis indicated in maximum parsimony reconstructions under the assumption of accelerated gain and putative secondary lost of apomixis. Values above branches indicate probability for ancestral apomixis in the clades depicted as triangles and branches leading to these clades (with $<0.01$ as the minimum value shown). The grey vertical lines indicate known for enhancement of the monsoon regimes in SE Asia. Abbreviations: CD: Cyrtomidictyum, CY: Cyrtomium, PH: Phanerophlebia, PO1: Polystichum clade 1, and PO2: Polystichum clade 2. C1 includes Cyrtomium species with mainly apomictic reproduction such as $C$. falcatum, C. fortunei, and C. macrophyllum, whereas C2 includes Cyrtomium known to show sexual reproduction such as C. grossum and C. nephrolepioides, as well as the apomictic C. hemionitis. X1 includes the apomictic taxa Polystichum luctuosum, $P$. tsus-simense, and P. xiphophyllum, whereas X2 includes the apomictic P. neolobatum and the nonapomictic P. hillebrandii.

in Polystichum polyblepharum [39] to be an example of laboratory-induced apomixis. However, we are only interested in cases in which apomictic taxa have originated spontaneously in nature.

In many cases, diploid chromosome number can be an indicator of sexual reproduction but diploid apomictic ferns have been discovered in several groups [19, 23, 58]. In such cases, it is not always certain that all individuals of a morphological defined species reproduce either sexually or asexually. The results may also be biased by the putative ecological advantages of apomictic taxa when compared to their sexual relatives. They may contribute to unbalanced sampling probabilities, that is, a high probability of sampling the common apomictic taxa versus a low probability of collecting the rare sexual taxa. The inferences made in this study do not account for these uncertainties. They may therefore result in a higher frequency of observed transitions from apomixis to sexual reproduction than expected.
Only unidirectional transition from sexual reproduction to apomixis has been recorded in ferns, suggesting that observations of the reverse transitions in the results of this study are artefacts of our methodology.

Incomplete taxon sampling may have influenced our findings that apomixis has little to no effect on speciation and extinction rates. Neither the large nor the small taxa set is close to representing the species of these genera. Our results therefore need to be tested on a more comprehensive sampling effort in the future. This problem is particularly important under the model of postorigin differentiation of apomictic taxa because the phylogenies used here are likely to underestimate the number of biological entities present. Evidence for this process was reported for the Cyrtomium fortunei complex [63]. Despite these limitations, our results are consistent with the hypotheses for the rare establishment of asexual lineages and a generally high extinction risk in these lineages [3]. 


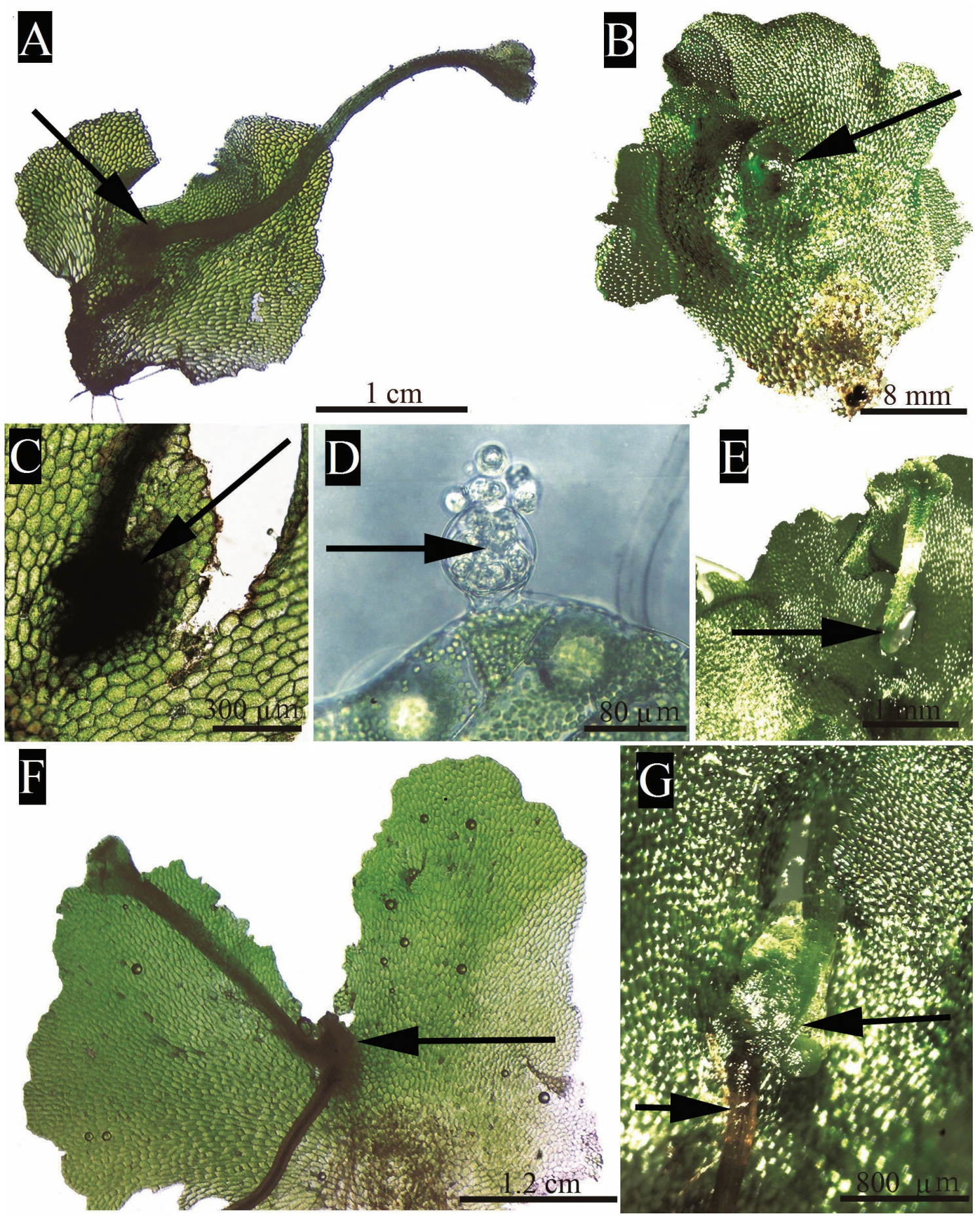

FIgURE 3: Apomictic reproduction in Cyrtogonellum caducum, observation from gametophyte cultures obtained from spores of GZYLB. (A) Heart-shaped prothallium with rhizoids (bottom of the image) and sporophytic outgrowth (arrow). (B) Close up of the early stage sporophytic outgrowth without differentiated organs (arrow), no indication for any archegonium was recovered. (C) Early stage of sporophytic outgrowth developed from somatic cells (arrow). (D) Close up of a mature antheridium (arrow) with spermatozoids. (E) Close up of the sporophytic outgrowth (arrow) with the differentiation of the first leaf. (F) Close up of the prothallium showing a slightly older sporophytic outgrowth (arrow) with one leave and one root located closely to the notch. (G) Sporophytic outgrowth at the notch of the gametophyte (upper arrow); the first root is already developed (lower arrow). 
Our results are also consistent with the hypothesis of young (in geological time), recurrently formed apomictic taxa. The divergence estimates did not recover evidence for apomictic lineages that originated more than 8 million years before the present (Figure 2). These results are consistent with other published results [5] and theoretical expectations [3]. The individual age of each apomictic lineage may be still much younger given that apomixis is likely to have been established multiple times in each of these clades.

All polystichoid clades comprising apomictic taxa occur either exclusively or predominantly in SE Asia [27, 30, $31,34]$, which was recognized as the center of diversity and putative area of origin of polystichoid ferns [28]. Thus, it is likely that apomixis originated in SE Asia and has not been established during the colonization of other regions. The time interval for the establishment of apomictic lineages coincides with estimates for the rise of the Qinghai-Tibetan plateau and changes in the monsoon regimes in SE Asia [40]. The establishment of apomixis in polystichoid ferns may therefore be associated to the strengthened monsoon regimes, and thus associated to the increased seasonality of precipitation. The SE Asian monsoon hypothesis is consistent with some other observations of apomictic ferns. Apomixis is especially common among the xerophytic cheilanthoid ferns [17, 20-22]. Apomictic species of Aspleniaceae occur preferably in areas with season rainfalls such as parts of Africa, for example, Asplenium aethiopicum complex, and northern Central America, for example, Asplenium monanthes complex $[9,10]$. However, further detailed investigations are required to establish a close link between the evolution of apomixis in ferns and the strengthening of the monsoon climates in SE Asia. However, further investigation into the effect of selection on the establishment of apomixis requires caution because the causality may be much less clear than anticipated [64].

Although there is strong support for multiple origins of apomixis in polystichoid ferns, it does not sufficiently explain the assembly of the observed taxonomic and morphological variation in the core Cyrtomium and Cyrtogonellum clades. Segregation in apomictic lineages was recently documented for Cyrtomium fortunei [63]. This process may also contribute to the diversity of the Cyrtogonellum clade because our results suggest the possibility of a single origin of apomixis in this lineage. However, this could be also the result of unsampled sexual taxa, due to their rarity. Despite uncertainties, the segregation hypothesis currently appears to be the best explanation for this complex. Future studies should take into account the evidence for antheridia in apomictic reproducing gametophytes of Cyrtogonellum caducum. Sexual organs were reported to be absent in most apomictic ferns, especially those formed by the DöppManton pathway [9-12]. The formation of antheridia may result in the fertilization of sexual polystichoid ferns by spermatozoids formed by apomictic taxa. This process has not been convincingly investigated in ferns yet.

The documented phylogenetic pattern introduces new questions concerning the uneven distribution of apomixis in these ferns. Above, we explored various factors such as ecological spatial aspects and hybridization. However, not all lineages of polystichoids occurring in SE Asia contain apomicts. Thus, other factors require to be considered in addressing the observed clustering of apomixis in the phylogeny of ferns. Considering evidence in angiosperms [65-67], the study of genome structure and gene expression may result in the discovery of preadaptations to apomixis present in some ferns. However, the current evidence does not allow rejecting the hypothesis of a random evolution.

\section{Conclusion}

Our study supports a scenario in which apomixis was repeatedly established in fern lineages that experienced frequent reticulate evolution combined with polyploidization. The apomictic lineages showed no increase in speciation rate, instead all apomictic lineages appeared to be short lived despite some evidence for postorigin diversification. In general, the results support the hypothesis that apomictic ferns are evolutionary dead ends in the long term but maintain the short-term potential to be highly successful in particular ecological conditions such as climates with strong seasonality. Finally, the study adds to the rapidly growing number of studies showing the power of the comparative approaches using robust phylogenetic frameworks to infer key questions in macroecological and macroevolutionary research. So far, the waste majority of studies using phylogenetic evidence to study apomixis in ferns are focused on species complexes $[5,17-21]$. As shown here and in a study on the genus Pteris [23], studies focusing on speciesrich genera, families, or the whole phylogenetic tree of ferns will likely recover the answers to the core question: "why is apomixis so common in ferns?"

\section{Acknowledgments}

The authors thank several colleagues for discussions of various aspects addressed in this study in particular Tim Barraclough (London, UK), David Barrington (Vermont, USA), Vincent Savolainen (London, UK), and Xian-Chun Zhang (Beijing, China). The authors acknowledge also the helpful comments of one anonymous reviewer. The State Key Laboratory of Systematic and Evolutionary Botany, Institute of Botany, the Chinese Academy of Sciences financially supported this study (to H. M. Liu). H. Schneider acknowledges the Senior Visiting Professorship awarded by the Chinese Academy of Sciences.

\section{References}

[1] D. R. Marshall and A. H. D. Brown, "The evolution of apomixis," Heredity, vol. 47, pp. 1-15, 1981.

[2] M. Mogie, The Evolution of Asexual Reproduction in Plants, 1992.

[3] E. Hörandl, "A combinational theory for maintenance of sex," Heredity, vol. 103, no. 6, pp. 445-457, 2009.

[4] M. T. J. Johnson, R. G. FitzJohn, S. D. Smith, M. D. Rausher, and S. P. Otto, "Loss of sexual recombination and segregation is associated with increased diversification in evening primroses," Evolution, vol. 65, pp. 3230-3240, 2011. 
[5] J. B. Beck, M. D. Windham, and K. M. Pryer, "Do asexual polyploid lineages led short lives? A case study from the fern genus Astrolepis," Evolution, vol. 65, pp. 3217-3229, 2011.

[6] D. Fontaneto, E. A. Herniou, C. Boschetti et al., "Independently evolving species in asexual bdelloid rotifers," PLoS Biology, vol. 5, no. 4, pp. 914-921, 2007.

[7] T. Schwander, L. Henry, and B. J. Crespi, "Molecular evidence for ancient asexuality in timema stick insects," Current Biology, vol. 21, no. 13, pp. 1129-1134, 2011.

[8] W. Döpp, "Cytologische und genetische Untersuchungen innerhalb der Gattung Dryopteris," Planta, vol. 29, no. 4, pp. 481-533, 1939.

[9] I. Manton, Problems of Cytology and Evolution in the Pteridophyta, Cambridge University Press, New York, NY, USA, 1950.

[10] A. F. Braithwaite, "A new type of apogamy in ferns," New Phytologist, vol. 63, pp. 293-305, 1964.

[11] J. D. Lovis, "Evolutionary patterns and processes in ferns," Advances in Botanical Research, vol. 4, pp. 229-415, 1978.

[12] T. G. Walker, "Apomixis and vegetative reproduction in ferns," in Reproductive Biology and Taxonomy of Vascular Plants, J. G. Hawkes, Ed., pp. 152-161, Botanical Society of the British Isles, Middlesex, UK, 1966.

[13] C. H. Park and M. Kato, "Apomixis in the interspecific triploid hybrid fern Cornopteris christenseniana (Woodsiaceae)," Journal of Plant Research, vol. 116, no. 2, pp. 93-103, 2003.

[14] U. Grossniklaus, G. A. Nogler, and P. J. Van Dijk, "How to avoid sex: the genetic control of gametophytic apomixis," Plant Cell, vol. 13, no. 7, pp. 1491-1497, 2001.

[15] R. A. Bicknell and A. M. Koltunow, "Understanding apomixis: recent advances and remaining conundrums," Plant Cell, vol. 16, pp. S228-S245, 2004.

[16] H. Schneider, E. Schuetipelz, K. M. Pryer, R. Cranfill, S. Magallón, and R. Lupia, "Ferns diversified in the shadow of angiosperms," Nature, vol. 428, no. 6982, pp. 553-557, 2004.

[17] A. L. Grusz, M. D. Windham, and K. M. Pryer, "Deciphering the origins of apomictic polyploids in the Cheilanthes yavapensis complex (Pteridaceae)," American Journal of Botany, vol. 96, no. 9, pp. 1636-1645, 2009.

[18] Y. M. Huang, S. Y. Hsu, T. H. Hsieh, H. M. Chou, and W. L. Chiou, "Three Pteris species (Pteridaceae: Pteridophyta) reproduce by apogamy," Botanical Studies, vol. 52, no. 1, pp. 79-87, 2011.

[19] J. Schneller and K. Krattinger, "Genetic composition of Swiss and Austrian members of the apogamous Dryopteris affinis complex (Dryopteridaceae, Polypodiopsida) based on ISSR markers," Plant Systematics and Evolution, vol. 286, no. 1-2, pp. 1-6, 2010.

[20] J. B. Beck, P. J. Alexander, L. Alphin et al., "Does hybridization drive the transition to asexuality in diploid Boechaera?" Evolution, vol. 66, no. 4, pp. 985-995, 2012.

[21] J. B. Beck, M. D. Windham, G. Yatskievych, and K. M. Pryer, "A diploids-first approach to species delimitation and interpreting polyploid evolution in the fern genus Astrolepis (pteridaceae)," Systematic Botany, vol. 35, no. 2, pp. 223-234, 2010.

[22] E. M. Sigel, M. D. Windham, L. Huiet, G. Yatskievych, and K. M. Pryer, "Species relationships and farina evolution in the cheilanthoid fern genus Argyrochosma (Peridaceae)," Systematic Botany, vol. 36, no. 3, pp. 554-564, 2011.

[23] Y. S. Chao, H. Y. Liu, Y. C. Ching, and W. L. Chiou, "Polyploidy and speciation in Pteris (Pteridaceae)," Journal of Botany, vol. 2012, Article ID 817920, 7 pages, 2012.
[24] P. S. Soltis and D. E. Sotlis, "Evolution of inbreeding and outcrossing in ferns and fern-allies," Plant Species Biology, vol. 5, pp. 1-11, 1990.

[25] E. R. J. Wubs, G. A. De, H. J. During et al., "Mixed mating system in the fern Asplenium scolopendrium: implications for colonization potential," Annals of Botany, vol. 106, no. 4, pp. 583-590, 2010.

[26] E. Hörandl, "Evolution and biogeography of alpine apomictic plants," Taxon, vol. 60, no. 2, pp. 390-402, 2011.

[27] D. P. Little and D. S. Barrington, "Major evolutionary events in the origin and diversification of the fern genus Polystichum (Dryopteridaceae)," American Journal of Botany, vol. 90, no. 3 , pp. 508-514, 2003.

[28] C. X. Li, S. G. Lu, and Q. Yang, "Asian origin for Polystichum (Dryopteridaceae) based on $\mathrm{rbcL}$ sequences," Chinese Science Bulletin, vol. 49, no. 11, pp. 1146-1150, 2004.

[29] C. X. Li, S. G. Lu, and D. S. Barrington, "Phylogeny of Chinese Polystichum (Dryopteridaceae) based on chloroplast DNA sequence data (trnL-F and rps4-trnS)," Journal of Plant Research, vol. 121, no. 1, pp. 19-26, 2008.

[30] H. M. Liu, X. C. Zhang, Z. D. Chen, and Y. L. Qiu, "Inclusion of the eastern Asia endemic genus Sorolepidium in Polystichum (Dryopteridacae): evidence from the chloroplast $r b c L$ and atpB genes," International Journal of Plant Sciences, vol. 689, pp. 1311-1323, 2007.

[31] H. M. Liu, X. C. Zhang, W. Wang, and H. Zeng, "Molecular phylogeny of the endemic fern genera Cyrtomidictyum and Cyrtogonellum (Dryopteridaceae) from East Asia," Organisms Diversity and Evolution, vol. 10, no. 1, pp. 57-68, 2010.

[32] J. M. Lu, D. Z. Li, L. M. Gao, X. Cheng, and D. Wu, "Paraphyly of Cyrtomium (Dryopteridaceae): evidence from $r b c L$ and trnL-F sequence data," Journal of Plant Research, vol. 118, no. 2, pp. 129-135, 2005.

[33] J. M. Lu, D. S. Barrington, and D. Z. Li, "Molecular phylogeny of the polystichoid ferns in Asia based on $r b c L$ sequences," Systematic Botany, vol. 32, no. 1, pp. 26-33, 2007.

[34] H. E. Driscoll and D. S. Barrington, "Origin of Hawaiian Polystichum (Dryopteridaceae) in the context of a world phylogeny," American Journal of Botany, vol. 94, no. 8, pp. 14131424, 2007.

[35] L. R. Perrie, P. J. Brownsey, P. J. Lockhart, and M. F. Large, "Evidence for an allopolyploid complex in New Zealand Polystichum (Dryopteridaceae)," New Zealand Journal of Botany, vol. 41, no. 2, pp. 189-215, 2003.

[36] L. B. Zhang and H. He, "Polystichum speluncicola sp. nov. (sect. Haplopolystichum, Dryopteridaceae) based on morphological, palynological, and molecular evidence with reference to the non-monophyly of Cyrtogonellum," Systematic Botany, vol. 35, no. 1, pp. 13-19, 2010.

[37] J. M. Lu, X. Cheng, D. Wu, and D. Z. Li, "Chromosome study of the fern genus Cyrtomium (Dryopteridaceae)," Botanical Journal of the Linnean Society, vol. 150, no. 2, pp. 221-228, 2006.

[38] P. S. Soltis and D. E. Soltis, "Population structure and estimates of gene flow in the homosporous fern Polystichum munitum," Evolution, vol. 41, pp. 620-629, 1987.

[39] G. Migliaro, Y. Gabriel, and J. M. Galan, "Gametophyte development and reproduction of the Asian fern Polystichum polyblepharum (Roem. Ex Kunze) C. Presl, (Dryopteridaceae, Polypodiopsida)," Plant Biosystems, vol. 146, no. 2, pp. 368373, 2012. 
[40] Z. S. An, J. E. Kutzbach, W. L. Prell, and S. C. Porter, "Evolution of Asian monsoons and phased uplift of the HimalayaTibetan plateau since Late Miocene times," Nature, vol. 411, no. 6833, pp. 62-66, 2001.

[41] G. Yatskievych, "Antheridiogen response in Phanerophlebia and related fern genera," American Fern Journal, vol. 83, pp. 30-36, 1993.

[42] W. M. Bao, Q. X. Wang, and S. J. Dai, "Morphology and ontogeny of the gametophyte of Cyrtogonellum inaequale Ching," in Ching Memorial Volume, Beijing, China, 1999.

[43] X. Cheng and S. Z. Zhang, Index to Chromosome Numbers of Chinese Pteridophyta, 2010.

[44] M. Kato, N. Nakato, X. Cheng, and K. Iwatsuki, "Cytotaxonomic study of ferns of Yunnan, southwestern China," The Botanical Magazine Tokyo, vol. 105, no. 1, pp. 105-124, 1992.

[45] V. Raghavan, Developmental Biology of Fern Gametophytes, 1989.

[46] W. P. Maddison and D. R. Maddison, "Mesquite 2. 75: a modular system for evolutionary analysis," 2012, http://mesquiteproject.org/mesquite/mesquite.html.

[47] D. Posada, "jModelTest: phylogenetic model averaging," Molecular Biology and Evolution, vol. 25, no. 7, pp. 1253-1256, 2008.

[48] D. L. Swofford, PAUP*. Phylogenetic Analysis Using Parsimony (* and Other Methods). Version 4, Sinauer Associates, Sunderland, Mass, USA, 2003.

[49] S. Guindon, J. F. Dufayard, V. Lefort, M. Anisimova, W. Hordijk, and O. Gascuel, "New algorithms and methods to estimate maximum-likelihood phylogenies: assessing the performance of PhyML 3.0," Systematic Biology, vol. 59, no. 3, pp. 307-321, 2010.

[50] A. J. Drummond, B. Ashton, S. Buxton et al., "Geneious v. 5. 4.," 2011, http://www.geneious.com/.

[51] F. Ronquist and J. P. Huelsenbeck, "MrBayes 3: bayesian phylogenetic inference under mixed models," Bioinformatics, vol. 19, no. 12, pp. 1572-1574, 2003.

[52] A. J. Drummond, M. A. Suchard, D. Xie, and A. Rambaut, "Bayesian phylogenetics with BEAUti and the BEAST 1. 7.," Molecular Biology and Evolution, vol. 29, no. 8, pp. 1969-1973, 2012.

[53] E. Schuettpelz and K. M. Pryer, "Evidence for a Cenozoic radiation of ferns in an angiosperm-dominated canopy," Proceedings of the National Academy of Sciences of the United States of America, vol. 106, no. 27, pp. 11200-11205, 2009.

[54] A. Rambaut and A. J. Drummond, "TRACER: MCMC Trace Analysis Tool v. 1. 5.," 2009, http://beast.bio.ed.ac.uk/.

[55] A. Rambaut, "FigTree 1. 31.," 2009, http://tree.bio.ed.ac.uk/.

[56] M. Christenhusz, H. Schneider, and X. C. Zhang, "A linear sequence of extant families and genera of lycophytes and ferns," Phytotaxa, vol. 19, pp. 7-54, 2011.

[57] A. R. Smith, K. M. Pryer, E. Schuettpelz, P. Korall, H. Schneider, and P. G. Wolf, "A classification for extant ferns," Taxon, vol. 55, no. 3, pp. 705-731, 2006.

[58] S. J. Lin, M. Kato, and K. Iwatsuki, "Diploid and triploid offspring of triploid agamosporous fern Dryopteris pacifica," The Botanical Magazine, vol. 105, no. 3, pp. 443-452, 1992.

[59] M. Pagel, "Detecting correlated evolution on phylogenies: a general method for the comparative analysis of discrete characters," Proceedings of the Royal Society B, vol. 255, no. 1342, pp. 37-45, 1994.
[60] W. P. Maddison, P. E. Midford, and S. P. Otto, "Estimating a binary character's effect on speciation and extinction," Systematic Biology, vol. 56, no. 5, pp. 701-710, 2007.

[61] S. Lehtonen, "Towards resolving the complete fern tree of life," PLoS ONE, vol. 6, no. 10, Article ID e24851, 2011.

[62] H. V. Hunt, S. W. Ansell, S. J. Russell, H. Schneider, and J. C. Vogel, "Dynamics of polyploid formation and establishment in the allotetraploid rock fern Asplenium majoricum," Annals of Botany, vol. 108, no. 1, pp. 143-157, 2011.

[63] R. Ootsuki, H. Sato, N. Nakato, and N. Murakami, "Evidence for genetic segregation in the apogamous fern Cyrtomium fortunei (Dryopteridaceae)," Journal of Plant Research, vol. 125, no. 5, pp. 605-612, 2012.

[64] E. Hörandl, C. Dobeš, J. Suda et al., "Apomixis is not prevalent in subnival to nival plants of the European Alps," Annals of Botany, vol. 108, no. 2, pp. 381-390, 2011.

[65] P. J. van Dijk and K. Vijverberg, "The significance of apomixis in the evolution of the angiosperms: a reappraisal," Regnum Vegetabile, vol. 143, pp. 101-116, 2005.

[66] J. G. Carman, "Asynchonous expression of duplicate genes in angiosperms may cause apomixis, bispory, tetraspory, and polyembryony," Biological Journal of the Linnean Society, vol. 61, no. 1, pp. 51-94, 1997.

[67] D. Haig and M. Westoby, "Genomic imprinting in endosperm: its effect on seed devlopment in crosses between species, and between different ploidies of the same species, and its implications for the evolution of apomixis," Philosophical Transactions of the Royal Society London Series B, vol. 333, pp. $1-13,1991$. 

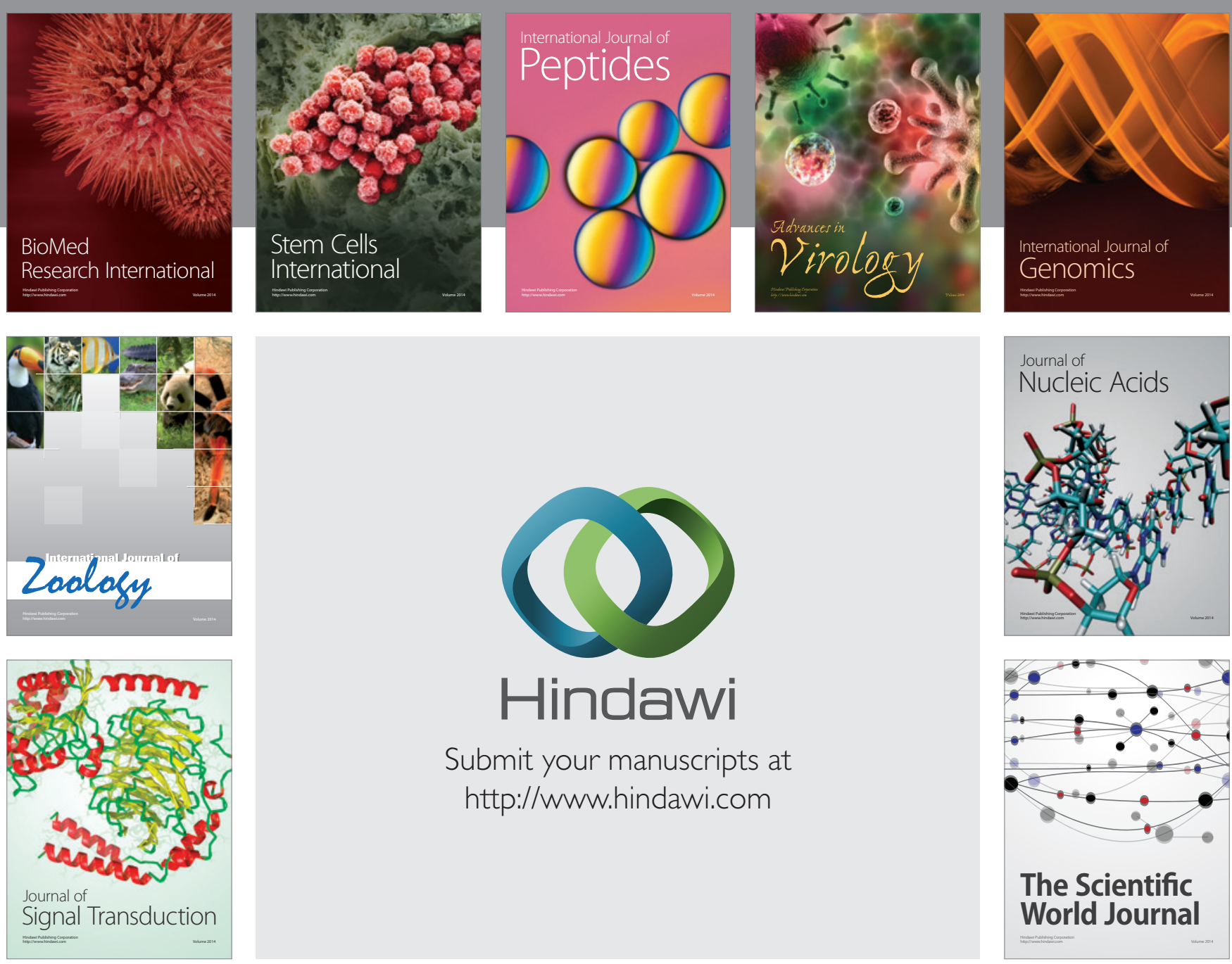

Submit your manuscripts at

http://www.hindawi.com
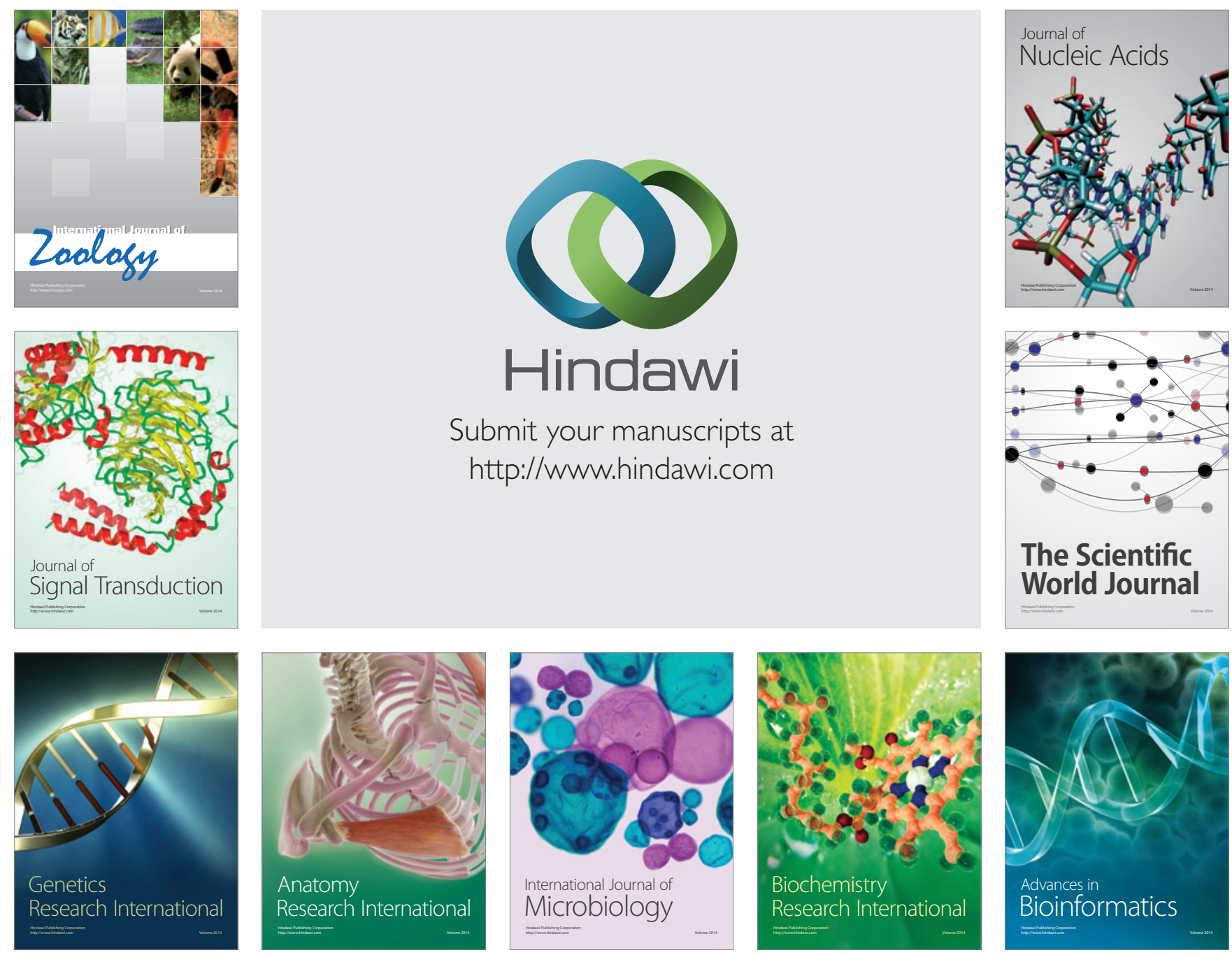

The Scientific World Journal
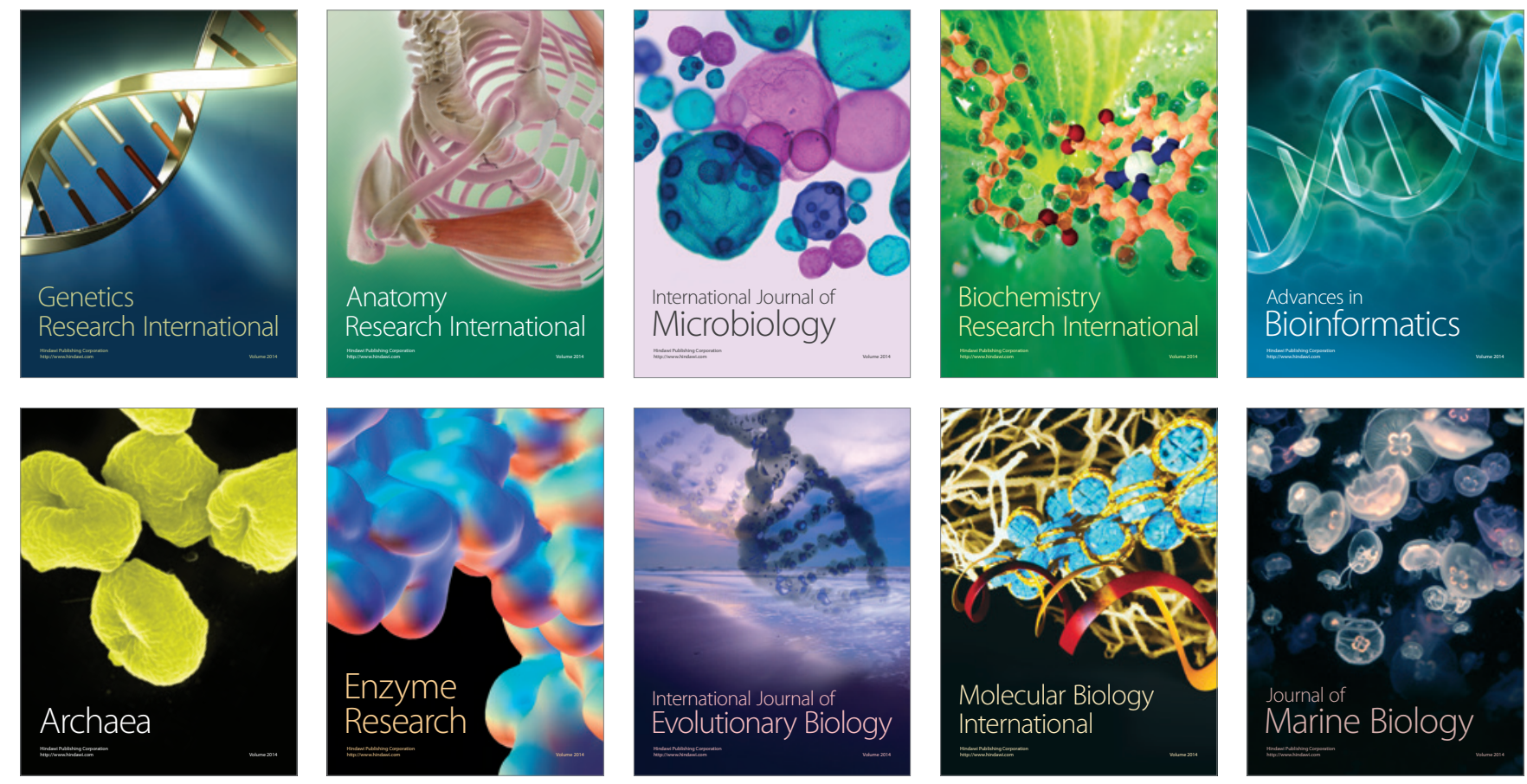